\title{
The use of modelling to implement the Water Framework Directive
}

\author{
M. Hartnett ${ }^{1}$, A. Berry ${ }^{2} \&$ K. Irvine ${ }^{3}$ \\ ${ }^{I}$ Department of Civil Engineering, National University of Ireland, \\ Galway, Ireland \\ ${ }^{2}$ MarCon Computations International Ltd., Newcastle, Galway, Ireland \\ ${ }^{3}$ Trinity College, Dublin, Ireland
}

\begin{abstract}
In December 2000 the European Parliament and Council passed into law the EC Directive 2000/60/EC establishing a framework for Community action in the field of water policy, commonly known as the Water Framework Directive (WFD). One of the primary objectives of the Directive is to achieve good ecological status for all waters. The methodologies being adopted by member states are varied using the most appropriate tools; it is specified that one such tool that should be used is numerical modelling. The research reported upon in this paper is the result of a project that was commissioned by the Irish EPA to investigate the role of mathematical modelling in implementing the WFD. The project took account of all categories of models including models of: anthropogenic pressures and impacts: diffuse pollution sources from land; hydrology/hydrogeology/hydrodynamics; dispersion and mass transfer; water quality; nutrient dynamics; eutrophication processes and aquatic ecosystems. Both inland and tidal waters were covered. The research carried out detailed a review of models and discuss their appropriateness for use. One of the main conclusions arising out of this work was detailing the specific areas within the WFD that would benefit from the use of the application of mathematical modelling.
\end{abstract}

Keywords: Water Framework Directive, modelling, nutrients, heavy metals, GIS, rivers, estuaries, integration. 


\section{Introduction}

The WFD places water within the context of the catchment through the implementation of River Basin Management Plans (RBMPs), developed for each designated River Basin District (RBD). The WFD will be the effective document under which national legislation will address quality issues within rivers, lakes, transitional waters (mainly estuaries), coastal waters and groundwaters. It also addresses those pressures within the catchment that lead to deterioration or provide risk to water and its ecology. The WFD has major implications for the sustainable management of both terrestrial and aquatic habitats and requires an approach that necessitates considerable development in the understanding of pressures and impacts on waters and the response of aquatic systems to programmes of measures designed to restore waters of less than good status. There is, therefore, more than an implicit requirement to develop tools to predict the response of surface and groundwaters, and the ecological communities that depend on them, to both increases and decreases in anthropogenic pressures.

The implementation of the WFD requires a holistic approach to catchment management that is effected through a more classical reductionism in order to understand salient physical, chemical and ecological mechanisms operating within each domain of the catchment. Within these various domains mathematical models should be utilised to provide synthesis of complex natural processes and to identify the likely response within and among domains of natural and anthropogenic changes. It is difficult to envisage cost-effective and meaningful management without such aids

\section{Why model?}

The use of appropriate mathematical models can help describe or predict ecological processes and response to natural driving variables or anthropogenic pressures. Models can guide management and policies and help in the design of monitoring programmes and interpretation of the results such programmes generate. Models can fill gaps in empirical data. The principles of why mathematical models are useful to the implementation of the WFD are succinctly outlined by Hession and Strorm [1]. Models can:

- $\quad$ help understand complex processes operating within the catchment;

- $\quad$ fill gaps in monitoring data;

- identify sources of pollution;

- $\quad$ predict system response to change; and

- evaluate management alternatives.

The commonly adopted DPSIR (Drivers, Pressures, State, Impact, Response) framework can be applied to identify the modelling processes applicable to the WFD, see Figure 1. The Drivers are activities in the catchment that lead to pressures on water resources. For many activities, as illustrated in Figure 1, these pressures are, typically, measurable pollutant loads. For example, a pressure from agriculture may be increased nutrient loads. Increased nutrient loads alter 
concentration in the receiving waters, the extent of which is dependent on water body type, determined by climate and character of the catchment. This defines water body hydromorphology. Hydromorphology can be altered through physical modifications of water courses (e.g. channelisation) or land (e.g. drainage). These factors collectively moderate the transfer of pollutant load to in situ concentration. This later factor can be considered to represent the State. It is for this reason that Characterisation of catchments, including the identification of water body types, is an important requirement (as described in Article 5) of the WFD. The link between Load and State often involves a series of mechanisms of varying complexity. The quantification of load-state can be assisted greatly by mathematical models. Similarly, the effect of pollutant concentration on ecology is moderated by physical, chemical and biotic processes. These are often complicated and multifaceted and, again, mathematical models can be employed to quantify and predict Impacts. The translation of State to Impact also depends on hydromorphology, which requires monitoring under Article 8 and Annex V of the WFD.

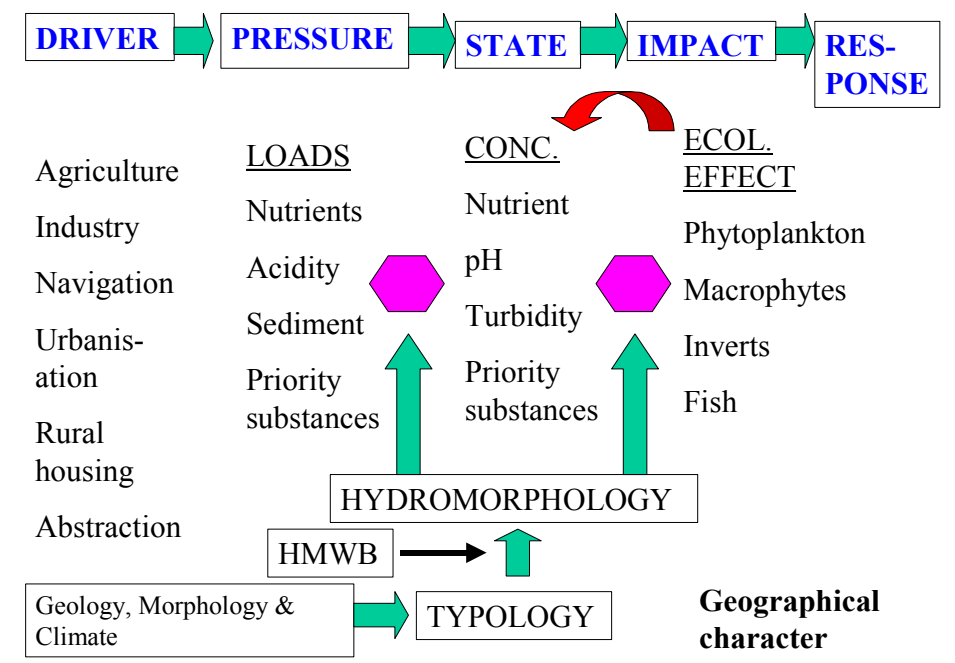

Figure 1: DPSIR framework.

Some pressures may not, however, impact directly on chemical concentration, but directly on ecology. Pressures from abstraction of groundwater may impact upon quantitative supply of water to wetlands. Pressures from commercial fishing may have direct ecological effect on abundance and size structure of fish populations. Hence, while the DPSIR model provides useful guidance, it does not necessarily incorporate the whole Pressure to Impact sequence. The Response within the DPSIR framework can be interpreted as synonymous with a Programme of Measures, as required under Article 11 of the WFD. A response to impact, can however, be implemented at each stage of the DPSIR sequence, as 
discussed below. Response can also be affected in anticipation of impact and based on risk analysis. The recognition of this option in catchment management is particularly important as a safeguard to high quality waters. A strategy of safeguard can, too, be assisted by mathematical models.

Mathematical models fall into a number of generic types that assemble and use data in different ways. All models have a domain, which provides the boundaries within which they were designed. Operating outside the defined domain is ill-advised. Model development, however, often comprises hierarchical building blocks employing an array of methods and scales (e.g. bench scale, small field, laboratory mesocosm, field studies) in order to provide a conceptual model of the system Kemp et al. [2]. A good conceptual model is essential for the successful application of modelling which, itself, can help develop the concepts. A major distinction often made between models is the division into the, so called, empirical models or the process models. Empirical models provide relationships between variables without taking into account the dynamics of the processes modelled. They are based only on statistical or judgemental summary of data and generally predict the magnitude of a response variable to a change in a driving variable. Time-variant processes are not identified separately, but may be incorporated through amalgamation into long time-steps, such as annual means, to provide estimates of steady-state. In contrast, process (also known as dynamic or deterministic) models are very much concerned with changes of variables over time and generally depend on mathematical descriptions of the processes involved. They are based strictly on scientific theory with processes described typically by scientifically reasonable equations. For example, they may include in the model such processes as change in partitioning of a chemical between states in response to ambient conditions or rate of transport through a system by advection-dispersion. Spatial resolution of models is also important, with broad distinction between lumped and distributed models which describes the extent to which models addresses areas, such as land-use categories, as homogenous units as opposed to treating, and modelling, spatial units separately. Broadly, model complexity and data requirements, increase with spatial and temporal resolution.

The factors that guide the selection of an appropriate model or models relate to 1) applicability, 2) data requirements and 3) ease and cost of use, including necessary provisions for training. Complex mathematical models may not be transparent in their working and, therefore, difficult to explain to a non-technical audience. Models which require extensive and detailed data may not be feasible for operational purposes, unless they can reliably depend on one-off calibrations and validations. Simple models, on the other hand, may not be sufficiently intricate to be generally useful. For both complex and simple models, appropriate formulation of processes are important Håkanson [3], in order to provide a realistic conceptual model.

Applicability of models need to be guided by a realistic appreciation of what is required. Complex, data-hungry, models are not necessarily the best. Simple methods often suffice and are certainly appropriate where only rough or relative estimates are required and where overall estimates of annual net impact provides 
enough information to effect management USEPA [4]. Examples of simple methods would be nutrient export coefficient or simple regression models to predict nutrient loads. These can help particularly with catchment characterisation under Article 5 of the WFD as part of the risk assessment process that water bodies may fail to meet environmental objectives as outlined in Article 4 of the WFD. Both aspects can guide monitoring programmes required under Article 8 of the WFD. Where a more detailed understanding is required, such as where a pressure may have important seasonal components but where there is, nevertheless, no capacity to apply very detailed modelling, the use of 'midrange' models might be employed USEPA [4]. In implementation of the WFD it could be envisaged that such an approach may be needed in some operational or investigative monitoring. The most detailed models need only be applied to help management if it is clear that explicit analysis and understanding of underlying mechanisms are required. This could include a need to know high resolution temporal or spatial patterns of behaviour or impact of a pollutant. Under such circumstances, explicit process models (e.g. QUAL2E, HSPF, MODFLOW 3, MarGIS) can be powerful tools. Mid-range and complex modelling are likely to be required mainly for investigative monitoring (Article 8) and for the implementation of Programmes of Measures (Article 11) where the cause of the failure to meet the Environmental Objectives are uncertain or contentious.

\section{Model uncertainty}

A level of uncertainty applies to all models and application of any model should include testing and sensitivity analysis. Sensitivity analysis shows how variation of a single factor affects model outputs. Uncertainty affects data collection and all stages of the modelling process and tends to increase with both the number of processes that feed onto the model along the DPSIR chain, and with complexity within the relevant model domain. In predictive models, uncertainty arises from inherent variability in natural processes, model uncertainty and parameter uncertainty. While the importance of uncertainty analysis is well recognised it is usually not included in pollutant transport models. It is important to be aware of this omission because if variability of input variables are large, so too will be output predictability. Beck [5] and Håkanson [3] provide excellent discussion of this issue. If within ecosystem variability is large, many samples need to be analysed to provide a given, defined, level of certainty in a mean value. Combined spatial, temporal and analytical uncertainty may be particularly high for measurements of some of the most important chemical ecosystem drivers, e.g. total phosphorus. This has profound implications for the reliability of use of simple models that predict ecosystem response from, e.g. nutrient loadings. As Håkanson [3] states "data from specific sites and sampling occasions may represent the prevailing, typical conditions [in the lake] very poorly indeed". Model uncertainty is clearly of importance in the conceptualisation of the process for which predictions are required. For example, a one-dimensional hydrological model would be expected to have greater predictive power than an 
ecological food-web systems model for lakes. However it is possible that the impact on modelling of individual error terms may be overestimated compared with combined effect of pairs of related parameters, see Reckhow and Chapra [6]. However, it is also clear that error estimation is often neglected when it should not be. Increasingly, however, techniques such as Monte Carlo simulation are applied to predict frequency distribution of variables, especially in sparse data sets.

\section{Classification schemes}

The WFD requires that member states adopt reporting protocols that classify water bodies as either high, good, moderate, poor or bad. Classification will be based on a state-changed approach that assesses the departure of individual water bodies from a reference (high) state, defined by an Ecological Quality Ratios (EQR). Under the classification scheme currently proposed by the REFCOND CIS group there is likelihood for frequent misclassifications arising from inappropriate scoring of individual quality elements and statistical probability functions. The errors associated with classification schemes can be alarmingly high. Therefore, an understanding of the errors associated with misclassification is needed so as to design and implement cost-effective monitoring and assessment programmes. Annex V of the WFD allows that where there are no sites at reference condition, other options may use historical data, modelling or expert judgement to estimate reference conditions for some indicators. Modelling may assist not only with the identification of reference but also how to handle the monitoring data that determines an EQR.

It is perhaps ironic that while the WFD has forced a move away from a spatial-comparative system using fixed-boundary water quality criteria to classify sites, it nevertheless appears to readopt a similar, and less transparent, philosophy through an EQR approach. A probability approach to site classification recommended by Premazzi and Chiaudani [7] provided a better, but not generally adopted, option in respect of the OECD [8] type water quality classification schemes. Such an approach would also be a more realistic one for site classification under the WFD. The reporting requirements of the WFD, nevertheless, promote classification where sites will be "shoe-horned" to fit within administratively convenient boundaries. The view of typologies and recommendation for GIS support confirm this as the current reality. Real systems are variable, often stochastic, and certainly non-linear. The models that mimic them, and the statistics that provide confidence to model results increasingly incorporate such inconvenient factors. Application of models to the implementation of the WFD needs to embrace, rather than ignore, uncertainty and the challenges that poses for interpretation and reporting. It is worth bearing this is mind, irrespective of the constraints of reporting.

There is no single integrated model that can be applied universally throughout a catchment in order to meet the demands of the WFD, even if applied to specific types of waterbodies. BASINS is an integrated catchment model, that incorporates a number of submodels to model catchment run off (HSPF and 
SWAT) and water quality (QUAL2E) models. Catchment loading models AGNPS and GWLF also incorporate a number of submodels that address separate components of nutrient transport through catchments. The SOBEK family of models provide linkable modules for river and estuarine modelling. Whether incorporated under "one roof" or not, a modular approach to catchment modelling will probably remain the more attainable reality; whereby individual models are developed to operate independently within the relevant domain but such that they are able to link with other models within a wider multi-model system. This approach enables communication of models, and modellers, within catchments and is an important consideration in the EU funded HARMONIT project. In the Netherlands, adoption of a modular approach has facilitated cooperation among institutes, and this is considered to be a key factor in progressing the use of modelling in the implementation of the WFD. A modular approach does not, however, need to detract from a holistic view of the catchment and the cumulative impact that inherent uncertainties may have for either application of individual models or, comprehensive, catchment management.

One of the most innovative approaches to WFD water quality modelling has been the embedding of complex water models into GIS. MarGIS is a fully GIS embedded water quality model which has been developed for water quality managers with limited modelling experience (www.marcon.ie). This new system enables complex dynamically linked one and two-dimensional models to be developed of river-lake-transitional water systems. The components include hydrodynamics, water quality (nutrients), sediments and heavy metal modelling. The system is an integration of the one-dimensional model FASTER and the two-dimensional model DIVAST into the ArcGIS system.

\section{Modelling relevance to implementation of WFD}

The potential use of mathematical models in the implementation of the WFD is clearly large. It is not possible from this review or from the information currently being collected in large EU funded programmes to identify individual models as the most superior in any particular context. Indeed, comparison of models applied to the same situation is uncommon, see Valiela et al. [9]. However, current Irish ERTDI EPA projects are addressing this need in the area of phosphorus modelling, but the final results from such projects will become available only after the publication of this report. Large variability of outputs across models is not uncommon. More complex models may be more responsive and precise, but not necessarily more accurate or predictive. Recommendations for appropriate model use relate, therefore, to principles rather than specifics. Modelling is likely to be highly applicable and cost effective for a number of the early milestones of the WFD, see Table 1. As the process of WFD implementation in refined in the future, so too will be the contribution of modelling. 
Table 1: Likely areas where application of models can assist with fulfilment of early tasks identified as necessary towards implementation of the WFD.

\begin{tabular}{|c|c|c|c|}
\hline Task & Milestone & $\begin{array}{l}\text { Delivery } \\
\text { date }\end{array}$ & $\begin{array}{l}\text { Relevant } \\
\text { WFD Article }\end{array}$ \\
\hline $\begin{array}{l}\text { GIS mapping of catchments } \\
\text { and water bodies }\end{array}$ & 2004 (June) & 2004 & 5 \\
\hline Intercallibration exercise & 2003 & 2006 (June) & 5 \\
\hline $\begin{array}{l}\text { Determine typology and } \\
\text { reference conditions }\end{array}$ & 2004 (June) & 2004 & 5 \\
\hline Risk assessment & 2004 (June) & 2004 & 5 \\
\hline Ecological classification & 2005 (Sept) & 2006 & 8 \\
\hline $\begin{array}{l}\text { Design monitoring systems } \\
\text { and network }\end{array}$ & 2004 (June) & 2006 & 8 \\
\hline Consult stakeholders & 2006 & 2008 & 14 \\
\hline $\begin{array}{l}\text { Identify programmes of } \\
\text { measures }\end{array}$ & 2005 (Mar) & 2009 & 11 \\
\hline
\end{tabular}

The need to prioritise modelling needs is obvious, but opinion on that among all interested parties will almost certainly vary, and require discussion. It is the view of the authors that current modelling techniques are likely to be of particular importance for the implementation of the WFD in respect of the following.

- Identification of risk to ecological quality from catchment pressures. This should form part of the Characterisation process and relates to the legal requirement to identify water bodies that are at risk of failing to reach environmental objectives. It will use recent developments in GIS coverage.

- Hydrological regimes and estimation of annual nutrient loads.

- Assistance with elucidation, assessment and choice of Programmes of Measures, which necessitates a case-by-case approach.

- Definition of spatial and temporal resolution of monitoring systems for identification of hydromorphology, and chemical and ecological status.

- Determination of reference conditions and methodology for determining departure from reference state and Ecological Quality Ratios (EQR).

- Identification of appropriate temporal and spatial scales to model impact of catchment processes on pollutant loads.

- Modelling frameworks for selection and integration of models.

- Development of decision and user support, to include enhanced communication for widespread understanding and use of models and dialogue among stakeholders.

- Modelling of ecological systems response to state changes and management measures. 


\section{Conclusions}

The challenges of the WFD are significant and judicious use of mathematical models can help meet them. Like the integrated nature of the catchment or the WFD documentation, models provide one component of a much larger whole. Ultimately, it will be good management of catchment activities that reduces the risk of pollutant emission that will play the most significant role in the protection of European water resources. These principles are employed in industrial Environmental Management Systems, and translation to the context of catchment management makes complete sense. However, while there is uncertainty about the nature of pollutant movement through catchments, modelling can assist management pollutant transport and it is an essential tool in river basin management.

This research has identified many areas where modelling can be usefully employed. Through a series of recommendations and final discussion it has highlighted where modelling can be effectively used, where further development is required and where it fits in within the overall implementation of the WFD. In summary and final conclusion the following are key issues.

- Models are likely to be extremely valuable in the assessment of risk of water bodies failing to meet environmental objectives and in investigative monitoring.

- Risk assessment should employ models to target monitoring and Programmes of Measures.

- All models, and the measurements used to calibrate and validate them, have errors which need to be quantified and reported.

- Catchment and hydrological models are generally more well developed, and with greater consensus of applicability to the WFD, than ecological models.

- As determination, prevention and reduction of impact are the pillars of the WFD, there needs to be a greater emphasis on the development and application of ecological models to support the implementation of the WFD.

- The determination of reference conditions and EQRs across water body typologies provides a major challenge for which the development and application of models can be usefully targeted.

\section{Acknowledgement}

The Authors wish to thank the Irish EPA for funding this research under Research Contract No. 2002-W-DS/11.

\section{References}

[1] Hession, W. C. \& Strorm, D. E., Watershed-Level Uncertainties: Implications for Phosphorus Management and Eutrophication. Journal of Environmental Quality, 29, pp 1172-1179, 2000 
[2] Kemp, W. M., Boynton, W. R. \& Hermann, A. S., Simulation models of an Estuarine Macrophyte Ecosystem. In: Patten, B. C., Jørgensen, S. E. \& Auerbach, S. I. (Eds.), Complex Ecology. The fort-whole Relation in Ecosystems, Prentice Hall, New Jersey: 262-278, 1995.

[3] Håkanson, L., On the principles and factors determining the predictive success of ecosystem models, with a focus on lake eutrophication models. Ecological Modelling 121, pp 139-160, 1999.

[4] USEPA, Protocol for Developing Nutrient TMDLs. U.S. Environmental Protection Agency, Washington, 1999.

[5] Beck, M. B (1987). Water quality Modelling: A review of the analysis of uncertainty. Water Resources Research, 23, 1393-1442, 1987.

[6] Reckhow, K. H. and Chapra, S. C., Engineering approaches for Lake Management. Volume I: Data Analysis and Empirical Modeling. Butterworth Publishers, Boston, 1983.

[7] Premazzi, G. and Chiaudani, G., Ecological Quality of Surface Waters. Quality Assessment Schemes for European Community Lakes. Joint Research Centre, European Commission, Brussels, 1992.

[8] OECD, Eutrophication of Waters, monitoring assessment and control. Paris, Organisation for Economic Cooperation and Development, 1982.

[9] Valiela, I., Bowen, J. L. and Kroeger, D., Assessment of models for estimation of land derive nitrogen loads to shallow estuaries. Applied Geochemistry 17, 935-953, 2002. 